\title{
Neptune Aerocapture Systems Analysis
}

\author{
Mary Kae Lockwood* \\ NASA Langley Research Center, Hampton, Virginia, 23681-2199
}

\begin{abstract}
A Neptune Aerocapture Systems Analysis is completed to determine the feasibility, benefit and risk of an aeroshell aerocapture system for Neptune and to identify technology gaps and technology performance goals. The high fidelity systems analysis is completed by a five center NASA team and includes the following disciplines and analyses: science; mission design; aeroshell configuration screening and definition; interplanetary navigation analyses; atmosphere modeling; computational fluid dynamics for aerodynamic performance and database definition; initial stability analyses; guidance development; atmospheric flight simulation; computational fluid dynamics and radiation analyses for aeroheating environment definition; thermal protection system design, concepts and sizing; mass properties; structures; spacecraft design and packaging; and mass sensitivities.

Results show that aerocapture can deliver 1.4 times more mass to Neptune orbit than an all-propulsive system for the same launch vehicle. In addition aerocapture results in a 3-4 year reduction in trip time compared to all-propulsive systems. Aerocapture is feasible and performance is adequate for the Neptune aerocapture mission. Monte Carlo simulation results show $100 \%$ successful capture for all cases including conservative assumptions on atmosphere and navigation. Enabling technologies for this mission include TPS manufacturing; and aerothermodynamic methods and validation for determining coupled 3-D convection, radiation and ablation aeroheating rates and loads, and the effects on surface recession.
\end{abstract}

$\begin{array}{ll}\mathrm{A} & =\text { Area }\left(\mathrm{m}^{2}\right) \\ \alpha_{\text {trim }} & =\text { Trim Angle of Attack } \\ \mathrm{CA} & =\text { Axial Force Coefficient } \\ \mathrm{CBE} & =\text { Current Best Estimate } \\ \mathrm{CD} & =\text { Coefficient of Drag } \\ \mathrm{CFD} & =\text { Computational Fluid Dynamics } \\ \mathrm{CG}, \mathrm{cg} & =\text { Center of Gravity } \\ \mathrm{CL} & =\text { Coefficient of Lift }\end{array}$

\section{Introduction}

A EROCAPTURE significantly increases the mass that can be delivered in orbit at a destination with an atmosphere compared to an all-propulsive vehicle at the same destination with the same launch vehicle. Aerocapture utilizes aerodynamic forces on a vehicle during a single pass through a destinations atmosphere to capture into orbit about that destination, instead of a large propulsive delta $\mathrm{V}$ maneuver. An aerocapture flight profile schematic showing the primary aerocapture event sequence is shown in Fig. 1. ${ }^{1}$

Aerocapture at Neptune is characterized by high entry velocities $\left(28-30 \mathrm{~km} / \mathrm{sec}\right.$ inertial) into a $\mathrm{H}_{2} \mathrm{He}$ atmosphere, and capture into a high energy science orbit enabling Tritan flybys. Table 1 provides a comparison of the Neptune aerocapture reference mission, described in this paper, to a repre-

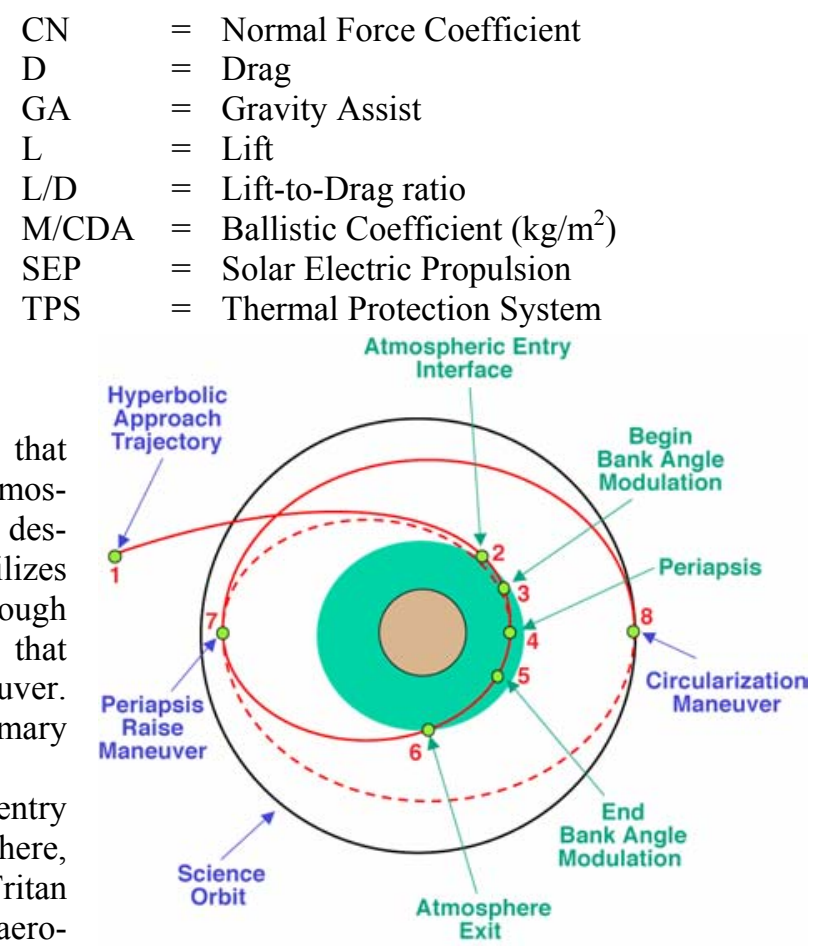

Figure 1. Aerocapture trajectory schematic.

\footnotetext{
* Aerospace Engineer, NASA Langley Research Center, Member AIAA.
} 
sentative Mars aerocapture mission, and a Titan aerocapture reference mission ${ }^{1}$. The high entry velocities at Neptune compared to Titan and Mars result in significantly more severe environments at Neptune, including both aeroheating and g's. The high energy science orbit for Neptune compared to the reference Titan and Mars missions, requires a significantly greater vehicle lift to drag ratio to provide adequate corridor width at Neptune.

Table 1 Neptune aerocapture parameters compared to those at Titan and Mars.

\begin{tabular}{|c|c|c|c|}
\hline & Neptune & Titan & Mars \\
\hline Entry Velocity (km/sec) & 29 & 6.5 & 5.7 \\
\hline Nom. Entry Flight Path Angle (deg) & -12.818 & -36 & -14.2 \\
\hline Apoapsis/Science Orbit $(\mathrm{km})$ & $3986 \times 430,000^{*}$ & 1700 & 1400 \\
\hline Atmosphere Composition (\% volume) & $\begin{array}{c}80 \% \mathrm{H} 2,19 \% \mathrm{He} \\
1 \% \mathrm{CH} 4\end{array}$ & $\begin{array}{c}95 \% \mathrm{~N} 2 \\
5 \% \text { CH4 (max) }\end{array}$ & $\begin{array}{l}95.3 \% \mathrm{CO} 2 \\
2.7 \% \mathrm{~N} 2\end{array}$ \\
\hline Atmos Scale Height at Aerocapture Alt (km) & 49 & 40 & 10.5 \\
\hline Atmospheric Interface Altitude $(\mathrm{km})$ & 1000 (above 1 bar) & 1000 & 125 \\
\hline Aerocapture Altitude $(\mathrm{km})$ & 100-300 (above 1 bar) & $200-400$ & 40 \\
\hline Aerocapture Exit/Escape Velocity & .97 & .69 & .76 \\
\hline $\mathrm{L} / \mathrm{D}$ & .8 & .25 & .25 \\
\hline $\mathrm{M} / \mathrm{CDA}\left(\mathrm{kg} / \mathrm{m}^{2}\right)$ & 895 & 90 & 148 \\
\hline Theoretical Corridor (deg) & 2.27 & 3.5 & $\sim 1.4$ \\
\hline Time from Atmos Entry to Atmos Exit (min) & 10 & 42 & 10 \\
\hline Convective Stag Point Heat Rate $\left(\mathrm{W} / \mathrm{cm}^{2}\right)$ & 8000 & $46(.91 \mathrm{~m}$ nose $\mathrm{rad})$ & 30 (1.9 m nose radius) \\
\hline Radiative Stag Point Heat Rate (W/ $\left.\mathrm{cm}^{2}\right)$ & $4000-8000$ & 93- 280 & Negligible \\
\hline Max g's During Aerocapture (Earth g's) & 22 & 3.5 & $2.5-3$ \\
\hline
\end{tabular}

* For set up of Triton flyby resonance at 488,000 or 393,000 km apoapsis

\section{Approach}

A multi-center aerocapture systems analysis team, including NASA engineers and scientists from Ames Research Center (ARC), the Jet Propulsion Laboratory (JPL), Johnson Space Center (JSC), Langley Research Center (LaRC), and Marshall Space Flight Center (MSFC), led by Langley Research Center, was kicked off in October 2002 and completed in October 2003. The effort was funded through the Code S In Space program.

The mission objectives and initial spacecraft design for the reference concepts are based on JPL's TeamX study ${ }^{2}$ of the Neptune Orbiter with probes mission. From this starting point, further science definition and initial analyses are completed to provide understanding of the vehicle requirements and selection of the reference concept and mission. Higher fidelity analyses are completed on the reference concept including mission design; aeroshell configuration screening and definition; interplanetary navigation analyses for determination of approach navigation delivery dispersions; atmosphere modeling; computational fluid dynamics (CFD) for aerodynamic performance and database definition; initial stability analyses; guidance development; atmospheric flight simulation; CFD and radiation analyses for aeroheating environments; TPS design, concepts and sizing; mass properties; aeroshell and spacecraft structural design and sizing; spacecraft design and packaging; and mass sensitivities.

\section{A. Science}

The Neptune mission includes a Neptune orbiter and two probes. The orbiter science mission includes two years in Neptune orbit. The science orbit is selected to enable Triton flybys. The Neptune Orbiter science instruments were selected to be representative, and include visible imager, IR imaging spectrometer, UV imaging spectrometer, thermal-IR imaging spectrometer, ion and neutral mass spectrometer, magnetometer, charged-particle detector, plasma wave spectrometer, microwave radiometer, USO (radio occultations) and two identical probes. ${ }^{3}$ 


\section{B. Mission Design and Reference Concept Selection}

Many alternate mission designs are considered, ${ }^{4}$ including launch on Delta IVH and Atlas 551; gravity assists utilizing various combinations of Venus, Earth and Jupiter; SEP at various power levels or chemical stages; and aerocapture versus chemical insertion. Launch dates after 2015 are considered, to provide time for technology development. An SEP, aerocapture system is baselined for the reference architecture.

The reference mission selected is a compromise between trip time, net delivered mass, inertial entry velocity, theoretical corridor width and aeroheating. Fig. 2 and 3 illustrate the net delivered mass and entry velocity vs. flight time for a range of SEP/aerocapture concepts. In general, as flight time decreases the net delivered mass decreases and entry velocity increases. The Delta IVH VJGA trajectories are selected for the reference mission concept based on delivered mass capability. Trip times less than 10 years are eliminated due to the rapid decrease in delivered mass capability and rapid increase in entry velocity (and corresponding aeroheating) with shorter trip times.

To further select a trip time, entry velocity, and required vehicle $\mathrm{L} / \mathrm{D}$, an initial trade in available corridor width as a function of vehicle $\mathrm{L} / \mathrm{D}$ and entry velocity is completed. Fig. 4 shows the theoretical corridor width vs. entry velocity and L/D for aerocapture into a $350,000 \mathrm{~km}$ apoapsis orbit at Neptune. The results in Fig. 4 illustrate several points. Theoretical corridor increases with both $\mathrm{L} / \mathrm{D}$ and entry velocity. An $\mathrm{L} / \mathrm{D}=0.8$ vehicle at 28 $\mathrm{km} / \mathrm{sec}$ provides approximately the same theoretical corridor width as an $\mathrm{L} / \mathrm{D}=0.6$ vehicle at slightly greater than $30 \mathrm{~km} / \mathrm{sec}$. In addition, to achieve reasonable theoretical corridor widths for aerocapture into the high energy elliptic orbit requires vehicles with significantly greater L/D than the high heritage blunt body configurations. (Ex., The theoretical corridor width is only approximately 0.8 degrees for an $\mathrm{L} / \mathrm{D}=0.25$ for a $70^{\circ}$ sphere cone.)

To provide an initial estimated theoretical corridor required for comparison to the available corridor width, a quick corridor margin analysis is completed for combinations of $\mathrm{L} / \mathrm{D}=0.6,0.8$ and 28 and 30 $\mathrm{km} / \mathrm{sec}$ entry velocity. The theoretical corridor must be adequate to accommodate dispersions, uncertainties, and variability in approach navigated states at atmospheric interface, aerodynamics, atmosphere, and guidance robustness. Initial estimates for navigated errors show $\pm .5^{\circ} 3 \sigma$ errors in entry flight path angle at $28 \mathrm{~km} / \mathrm{sec}$ and $\pm .6^{\circ} 3 \sigma$ errors in entry flight path angle at $30 \mathrm{~km} / \mathrm{sec}$. Aerodynamic uncertainties can be conservatively estimated to result in $\pm .2 \mathrm{~L} / \mathrm{D}$,

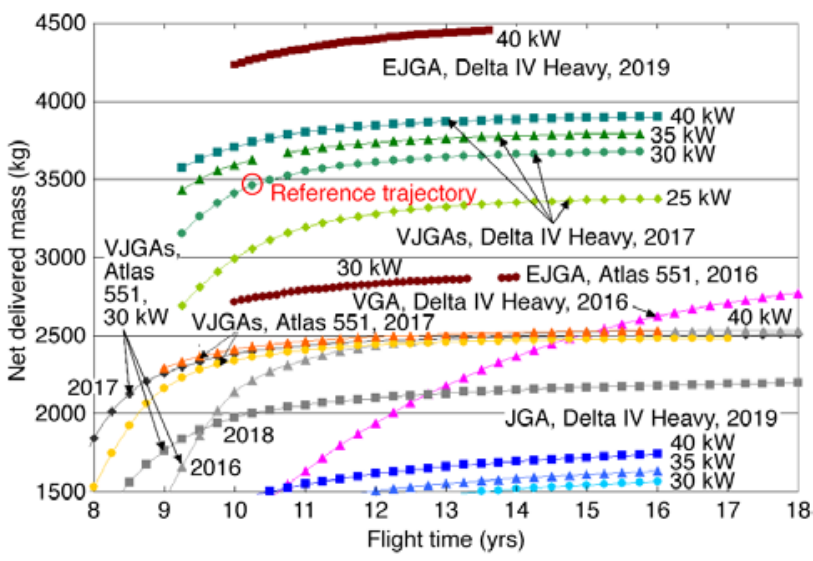

Figure 2. Delivered mass vs. trip time for a range of SEP/Aerocapture mission concepts considered. ${ }^{4}$

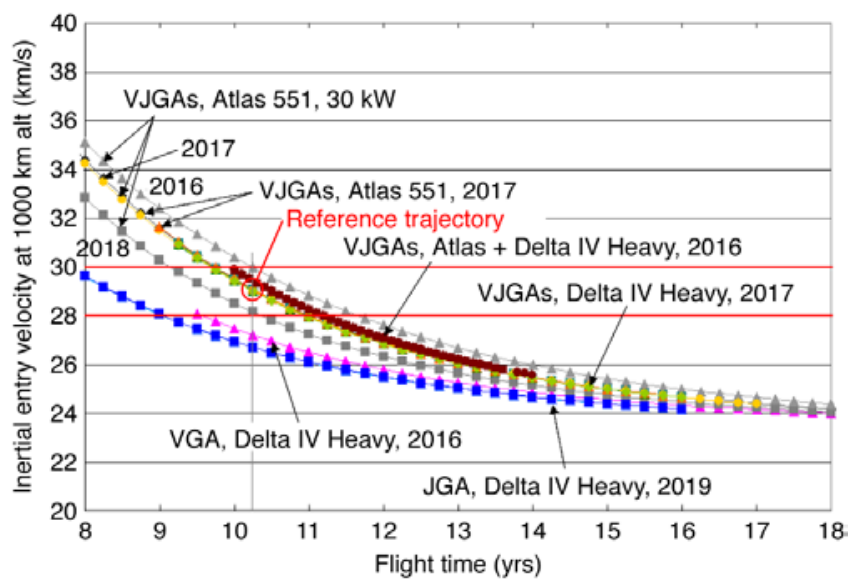

Figure 3. Entry velocity vs. trip time for a range of SEP/Aerocapture mission concepts considered. ${ }^{4}$

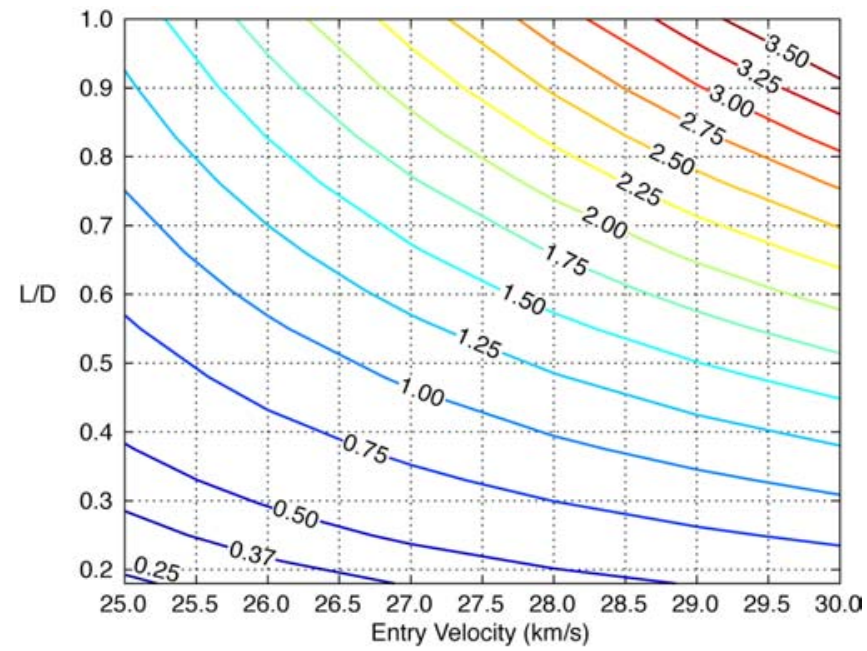

Figure 4. Theoretical corridor width available as a function of vehicle $L / D$ and entry velocity.

3

American Institute of Aeronautics and Astronautics 
guidance is estimated to capture $95 \%$ of theoretical corridor, and corridor loss due to total mean variability of the atmosphere is estimated using lift up and lift down trajectories at the global extremes of mean density in the initial NeptuneGRAM atmosphere model. Note that this approach does not account for high frequency variability in atmospheric density and the corresponding impact on vehicle performance and margin.

Results of this estimate are shown in Fig. 5 for the 4 cases considered, $\mathrm{L} / \mathrm{D}=0.6$ and $28 \mathrm{~km} / \mathrm{sec}, \mathrm{L} / \mathrm{D}=0.6$ and $30 \mathrm{~km} / \mathrm{sec}, \mathrm{L} / \mathrm{D}=0.8$ and 28 $\mathrm{km} / \mathrm{sec}, \mathrm{L} / \mathrm{D}=0.8$ and $30 \mathrm{~km} / \mathrm{sec}$. The $\mathrm{L} / \mathrm{D}=0.6$ and $28 \mathrm{~km} / \mathrm{sec}$ case show the estimated corridor loss due to approach navigated errors, aerodynamics uncertainty, and total mean atmosphere variability and uncertainty. If these losses are RSS'd a required theoretical corridor width can be estimated for use in comparison to the total available theoretical corridor width. For this

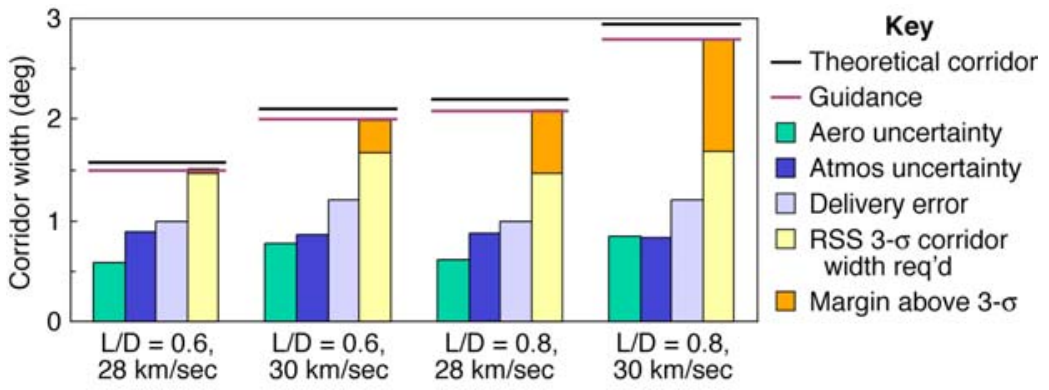

Figure 5. Estimated theoretical corridor width required compared to theoretical corridor width available. case, the required and available theoretical corridor widths are approximately the same, well within the accuracy of the estimate, and again, high frequency atmosphere perturbations are not included. Because of the early phase of design, the objective for selection of the reference concept is to select a concept with margin greater than the RSS required corridor width. As a result, an $\mathrm{L} / \mathrm{D}=0.8$ vehicle with a $29 \mathrm{~km} / \mathrm{sec}$ entry velocity is selected for the reference concept, with an $\mathrm{L} / \mathrm{D}=0.6$ vehicle kept as an option.

The reference concept is therefore described as follows. The mission launches February 17, 2017, on a Delta IV $\mathrm{H}$. The launch vehicle fairing is $5 \mathrm{~m}$ in diameter with a $4.572 \mathrm{~m}$ static payload diameter. The total launch capability is $5964 \mathrm{~kg}$, with a launch C3 of $18.44 \mathrm{~km} 2 / \mathrm{sec}^{2}$. The SEP system is a $30 \mathrm{~kW}$ EOL, 6 engine SEP system, that operates to $3 \mathrm{AU}$. A Venus, Jupiter gravity assist is utilized. The total trip time is 10.25 years, with Neptune arrival in 2027. Two probes are released at E-4 months (1 week apart). The probes enter at E-4 hours and E-2 hours. Aerocapture inertial entry velocity at Neptune is $29 \mathrm{~km} / \mathrm{sec}$, atmospheric interface is $1000 \mathrm{~km}$ above 1 bar. The orbit is $157^{\circ}$ retrograde, $430,000 \mathrm{~km}$ by $3986 \mathrm{~km}$. The science mission includes two years in Neptune orbit for a total 12.25 year Neptune Orbiter mission.

\section{Aeroshell Configuration}

Aeroshell configuration screening is completed to develop shapes with $\mathrm{L} / \mathrm{D}=0.8$, and $\mathrm{L} / \mathrm{D}=0.6$ as an option, while maximizing volumetric efficiency and minimizing M/CDA. Several aeroshell shape classes are considered including ellipsleds, flattened ellipsleds, high fineness sphere cones, biconics and bent biconics, as shown in Fig. 6. The vehicle mass and volume are fixed, the shapes within each vehicle configuration class are varied parametrically. Newtonian aerodynamics, varified with CFD, is utilized to screen the configurations for $\mathrm{L} / \mathrm{D}$ and $\mathrm{M} / \mathrm{CDA}$ over a range of angle of attack. Packaging efficiency is also screened through determination of vehicle volumetric efficiency. Based on these analyses, the flattened ellipsled is selected for the reference aeroshell configuration. Details of the configuration screening and vehicle selection are contained in Ref. 5.

\section{Design Cycles}

Two design cycles are completed for the Neptune Orbiter. The original objectives were to package 3 probes within the aeroshell of the orbiter. As a result the design cycle one vehicle is $5.5 \mathrm{~m}$ in length with $\mathrm{M} / \mathrm{CDA}$ estimated at $273 \mathrm{~kg} / \mathrm{m}^{3}$, and an aeroheating design trajectory developed at $400 \mathrm{~kg} / \mathrm{m} 2$ to provide mass growth margin. With this design, the system mass margin on the Delta IVH SEP VJGA was estimated to be less than the desired 35\%. In addition, further analysis shows that the science objectives can be met with the probes carried externally and released prior to aero-

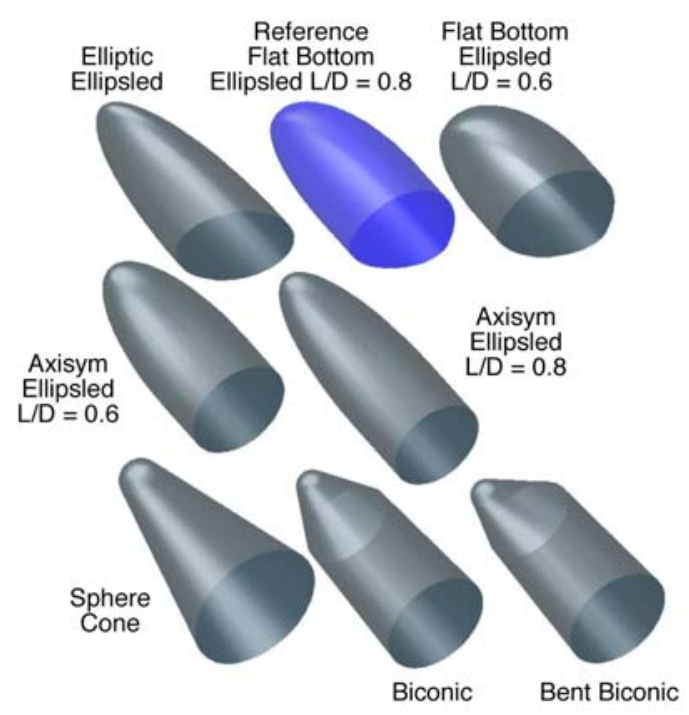

Figure 6. Configuration classes considered. 
capture. Two external probes are therefore included in the design cycle two concept. The aeroshell is photographically scaled from a $5.5 \mathrm{~m}$ length vehicle to a $2.88 \mathrm{~m}$ length, shown in Fig. 7. The entry allocation is $2200 \mathrm{~kg}$, resulting in a ballistic coefficient of $895 \mathrm{~kg} / \mathrm{m}^{2}$. This $\mathrm{M} / \mathrm{CDA}$ is used for both the performance analyses and the design trajectories for the aeroheating and structure design.

\section{E. Navigation}

Navigation analyses are completed at 28 and $30 \mathrm{~km} / \mathrm{sec}$ with the Mars Reconnaissance Orbiter camera and an Entry 3 day data cut-off. In addition, results are completed with an MRO camera with two times the pictures and with an advanced MRO camera. As a comparison results are also completed for an Entry 2 day data cut-off. Results are shown in Fig. 8. See Ref. 6 for detailed discussion on the navigation analysis and results.

Monte Carlo simulations are completed for the reference vehicle using $\pm .51^{\circ} 3 \sigma$ entry flight path angle dispersions. This is approximately equivalent to an MRO camera with $2 \mathrm{x}$ pictures or to an advanced MRO camera, each with a more conservative Entry -3 day data cutoff. A change to Entry -2 day cut-off significantly reduces the delivery entry flight path angle dispersions as shown in Fig. 8.

\section{F. Atmosphere Modeling}

A NeptuneGRAM ${ }^{7}$ atmosphere model is developed based on Voyager and other data. Variability includes all measurement uncertainty, residual uncertainty due to turbulence and waves, and the expected variability due to latitude, altitude, seasonal and time of day variations. The atmosphere composition is $80 \% \mathrm{H} 2, \sim 19 \% \mathrm{He}, \sim 1 \% \mathrm{CH} 4$. Fig. 9 illustrates the total mean density variability as a function of altitude. Note that the range of aerocapture altitudes is between approximately 100 and $300 \mathrm{~km}$. The parameter Fminmax is utilized to define the range of density profiles. The mean density profile is represented by Fminmax $=0$, the minimum density profile is represented by Fminmax $=-1$, and the maximum density profile is represented by Fminmax $=+1$.

Fig. 10 illustrates the latitudinal variation of density for the particular arrival season of the reference concept. This variation of Fminmax with latitude is represented by

$$
\text { Fminmax }=0.44 * \cos (4.0 * \text { latitude })+\text { fbias }
$$

where $-0.56>$ fbias $<0.56$

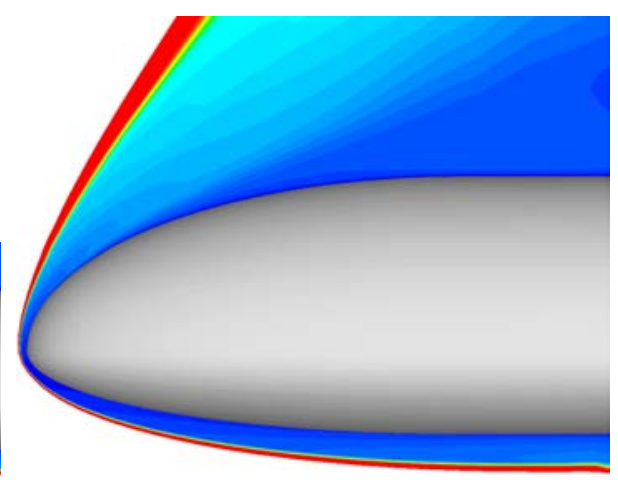

Figure 7. Comparison of Design Cycle 1 and Design Cycle 2 configuration scale.

Figure 8. Delivery flight path angle dispersions at atmospheric interface for various navigation scenarios.

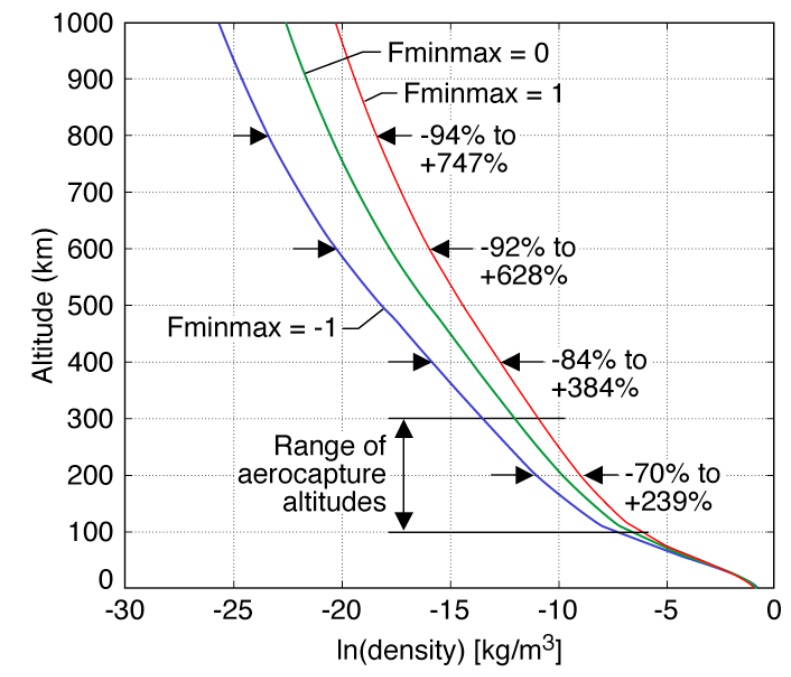

Figure 9. NeptuneGRAM mean density profile variability. ${ }^{8}$ 


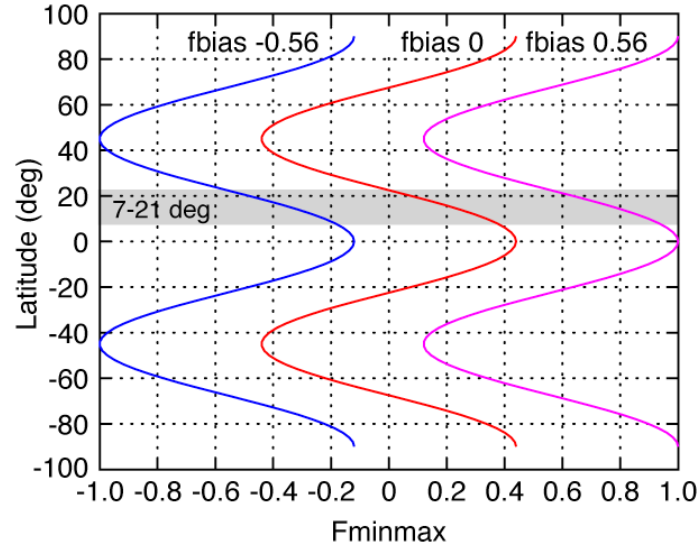

Figure 10. Effect of latitude on NeptuneGRAM mean density profile for Neptune Orbiter arrival date. ${ }^{8}$

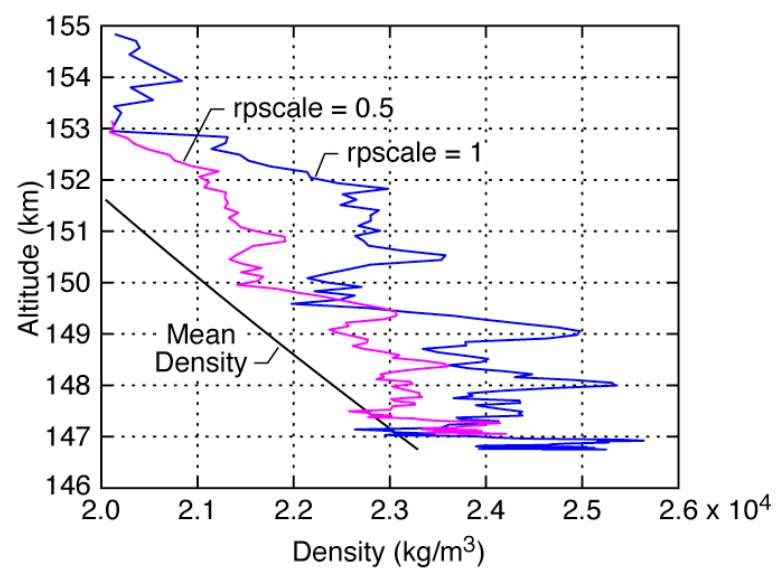

Figure 11. High frequency density perturbations in NeptuneGRAM. ${ }^{8}$

Therefore, for a typical Neptune aerocapture trajectory flying through the atmosphere between $7-21^{\circ}$ latitude, $0.6 \geq$ Fminmax $\leq 0.93$, compared to a range of $-1.0 \geq$ Fminmax $\leq 1.0$ for a global variation.

Fig. 11 illustrates a sample high frequency density perturbation compared to the mean density. The mean density corresponds to a given Fminmax value in Fig. 9. rpscale controls the high frequency variability of the atmosphere, with rpscale $=1$ representing the greatest expected variability for Neptune. The rpscale $=1$ results in Fig. 9, show a sample of how the high frequency content can alter the mean variability. Note that the high frequency content can act to increase or decrease the mean density with altitude, in addition to adding the high frequency content. Rpscale $=0.5$ represents a potential decreased high frequency content for the Neptune atmosphere.

The reference concept performance, as shown below, is based on the latitudinal variation of Fminmax and rpscale $=1$. Aeroheating and structure design trajectories are based on the full range of Fminmax and rpscale $=1$.

\section{G. Aerodynamics}

The aerodynamic database is developed from viscous LAURA CFD analysis of the reference configuration. ${ }^{5}$ The vehicle trims at $40^{\circ}$ angle of attack with an axial cg location relative to the vehicle length of $0.51 \mathrm{aft}$ of the nose, and a vertical cg relative to the vehicle length of .0166 below the vehicle waterline. For the trimmed vehicle $\mathrm{L} / \mathrm{D}=0.806, \mathrm{CD}=1.405, \mathrm{CL}=1.133$. Initial stability analysis shows that the flat-bottom ellipsled is longitudinally and laterally stable. ${ }^{5}$

The aerodynamic uncertainties are based on the JSC ellipsled analysis for Mars, consistent with the X-33 aerodynamic database uncertainty model in Ref. 9. As shown in Fig. 12, CA: \pm 0.048 and $\mathrm{CN}: \pm 0.12$, each using base area as the reference. The trim angle of attack uncertainty is assumed to be $\pm 4^{\circ}$, defined in this initial analysis to be double that for a typical blunt body, such as a $70^{\circ}$ sphere cone. Cg uncertainties are $\pm 0.5 \%$ for axial cg relative to the vehicle length and $\pm 0.125 \%$ for radial cg relative to the vehicle length. Based on stacked aerodynamic uncertainties, the $\mathrm{L} / \mathrm{D}$ uncertainty is $+26.4 \%$ and $-22 \%$. Based on an RSS of the aerodynamic uncertainties, the L/D uncertainty is $+13.5 \%$ and $-14.3 \%$. The Monte Carlo variability for 2001 cases is between the RSS and stacked uncertainties. ${ }^{9}$

Note that the effects of large TPS recession and resultant shape change on the vehicle aerodynamics and cg location have not been quantified. This analysis was outside the study scope.

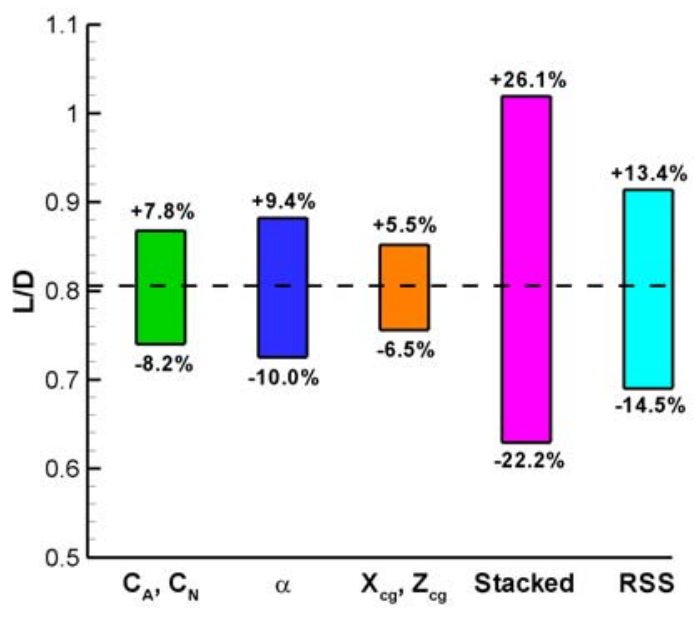

Figure 12. Aerodynamic uncertainties. ${ }^{5}$ 


\section{H. Guidance}

HYPAS guidance (ref. 10) was chosen for the Titan aerocapture systems analysis. HYPAS utilizes vehicle lift and bank angle control through the atmosphere to target the desired exit orbit apoapsis and inclination. It is an analytically derived algorithm based on deceleration due to drag and altitude rate error feedback. This analytic, noniterative, on-the-fly approach leads to efficient code ( $\sim 320$ source lines in Fortran), minimal storage requirements, and fast and consistent execution times.

HYPAS consists of two phases: 1) Capture Phase: Establishes pseudo-equilibrium glide conditions; 2) Exit Phase: Exit conditions are predicted analytically assuming a constant altitude rate followed by constant acceleration. The lift vector is adjusted to null the error between predicted and target apoapsis, and bank reversals are used to keep inclination errors within the desired limits. Results show excellent performance and an ability to capture $\sim 93 \%$ of the theoretical corridor.

\section{Performance/Simulation}

The reference concept performance is simulated in a Monte Carlo simulation ${ }^{8}$ and includes each of the uncertainties and dispersions as described above. Fig. 13a-d show the reference concept Monte Carlo results. The reference concept is an $\mathrm{L} / \mathrm{D}=0.8$ vehicle, with $\mathrm{M} / \mathrm{CDA}=895 \mathrm{~kg} / \mathrm{m}^{2}$. The target orbit, to enable Triton flybys, is retrograde with an apaopsis of 430,000 km, and a periapsis of $3986 \mathrm{~km}$. Uncertainties included in the Monte Carlo include navigation, with $\pm 0.51^{\circ} 3 \sigma$ entry flight path angle at atmospheric interface, atmosphere variability as a function of latitude and high frequency perturbations corresponding to rpscale $=1$, and aerodynamic uncertainties described

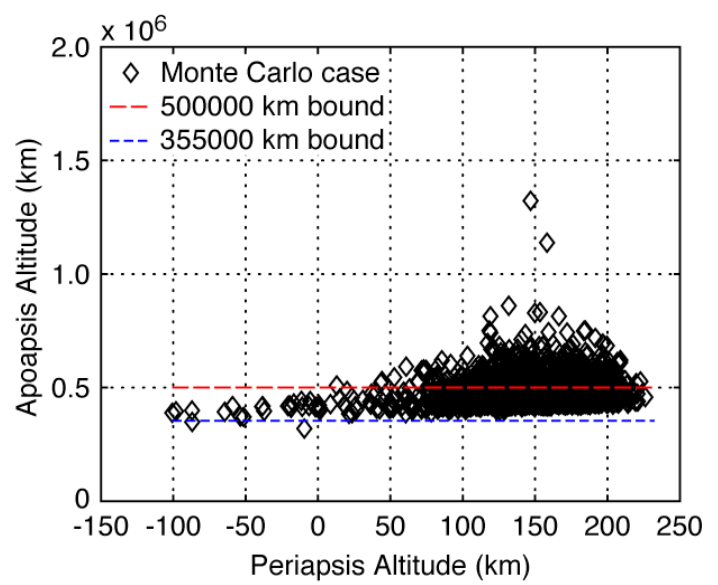

Figure 13a. Reference concept Monte Carlo results, apoapsis vs. periapsis. ${ }^{8}$

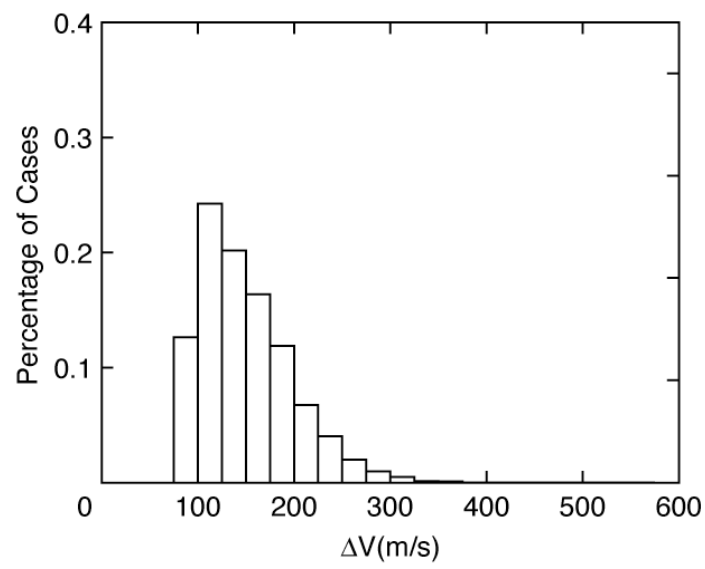

Figure 13b. Reference concept Monte Carlo results, delta $V$ req'd to raise periapsis and correct apoapsis. ${ }^{8}$

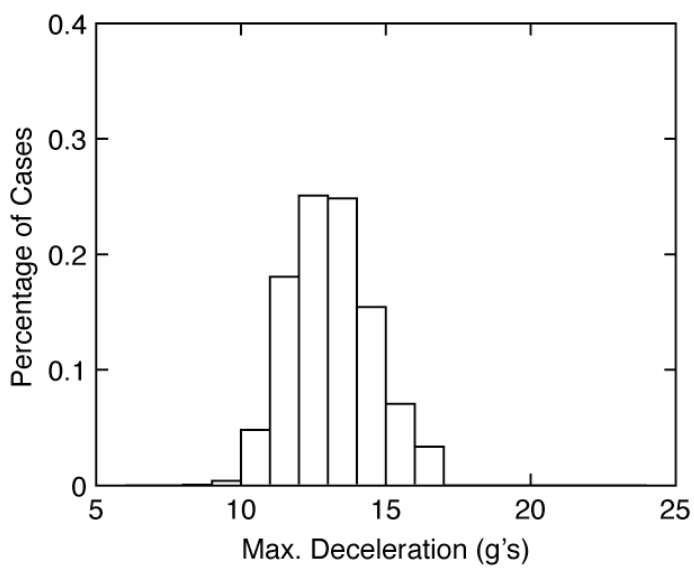

Figure 13c. Reference concept Monte Carlo results, heat load vs. peak heat rate. ${ }^{8}$

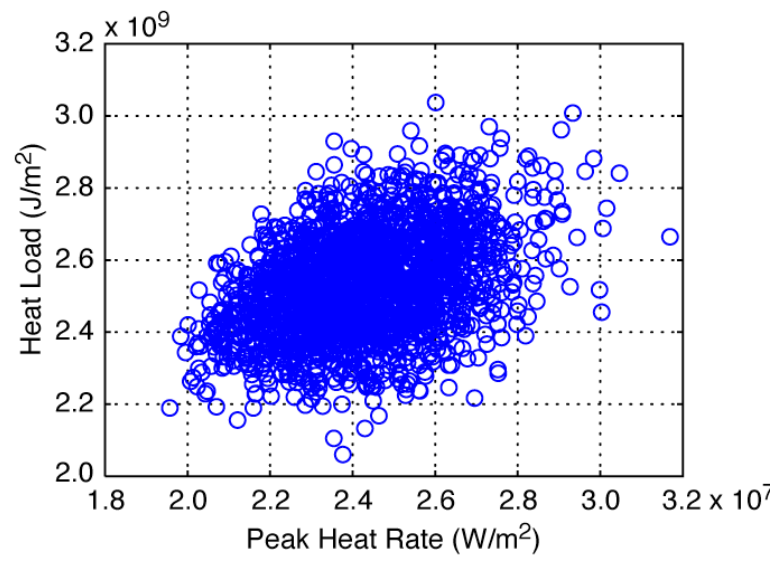

Figure 13d. Reference concept Monte Carlo results, heat load vs. peak heat rate. ${ }^{8}$ 
above.

All 2001 Monte Carlo trajectories successfully capture. Approximately $66 \%$ of the cases achieve apoapsis within the apoapsis target range of $355,000 \mathrm{~km}$ and $500,000 \mathrm{~km}$. In each of the Monte Carlo cases an apoapsis correction delta $\mathrm{V}$, along with the periapsis raise delta $\mathrm{V}$, is utilized to correct the orbit to the target of 430,000 by $3986 \mathrm{~km}$. The total delta V, as shown in Fig. 13b, is $141 \mathrm{~m} / \mathrm{sec}$ for the mean for the combined periapsis raise and apoapsis correction and $360 \mathrm{~m} / \mathrm{sec} 99.87$ percentile. Figures $\mathrm{c}$ and d illustrate the entry g loading and the peak heat rate vs. total heat load based on a stagnation point convective indicator for a $1 \mathrm{~m}$ nose radius. The $3 \sigma$ high g's are $17.6 \mathrm{~g}$ 's, which are less than the $22.1 \mathrm{~g}$ 's used to design the vehicle structure. The $3 \sigma$ high heat rate and heat load stagnation point convective indicators are $2957 \mathrm{~W} / \mathrm{cm}^{2}$ and $295 \mathrm{~kJ} / \mathrm{cm}^{2}$, respectively, compared to the $3250 \mathrm{~W} / \mathrm{cm}^{2}$ and 290 $\mathrm{kJ} / \mathrm{cm}^{2}$ stagnation point convective rate and load indicators of the reference aeroheating design trajectory.

The apoapsis error (prior to delta V correction) for Neptune is greater than that seen in previous studies. Before any apoapsis correction, and a $430,000 \mathrm{~km}$ apoapsis target, the $3 \sigma$ range in Neptune apoapsis is 371,300 to $832,700 \mathrm{~km}$. For comparison the range in apoapsis at Titan, ${ }^{1}$ prior to any delta $\mathrm{V}$ to adjust apoapsis, and a $1700 \mathrm{~km}$ apoapsis target, is 1499 $\mathrm{km}$ to $1883 \mathrm{~km}$. The larger apoapsis errors at Neptune compared to Titan result from the high energy Neptune target orbit. At Neptune, the aerocapture exit velocity is very close to the Neptune escape velocity, resulting in a high sensitivity of apoapsis to aerocapture exit velocity. For example the ratio of the aerocapture exit velocity to escape velocity at Neptune is 0.97 . The aerocapture to escape velocity at Titan is $0.69 .^{10}$

The updated range of dispersions and uncertainties in navigation, aerodynamics, and atmosphere, are utilized in Fig. 13e, to assess the corridor margin for comparison to the

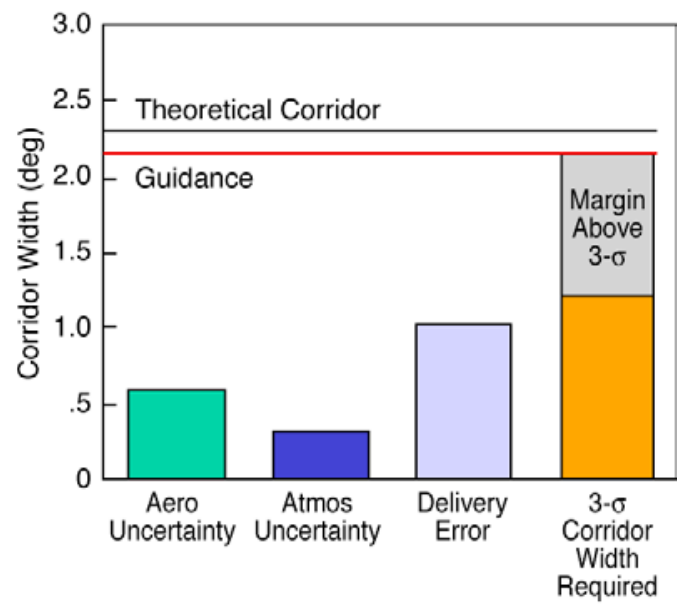

Figure 13e. Reference concept comparison of required vs. available theoretical corridor width. original estimates in Fig. 5. The stacked aerodynamic uncertainties are used, and are similar to the assumptions earlier. Note that the atmosphere uncertainties are significantly less than the initial estimates. This results from the reduced range of Fminmax, by incorporating the variation of density with latitude as opposed to utilizing a global range, and also due to the higher vehicle ballistic coefficient and reduced atmosphere variability at lower altitudes. The revised estimates show significant margin above the RSS value. The effects of high frequency density perturbations and additional aerodynamic uncertainties due to surface recession are not represented in the estimate, however. Results suggest that there may be margin in the performance design that could be utilized to reduce the vehicle L/D requirement, reduce the entry velocity or to accommodate increased atmosphere variability resulting from an increase vehicle size (and lower M/CDA) in an effort to reduce aeroheating.

\section{J. Angle of Attack Modulation Option}

Utilizing angle of attack control as an option to augment the bank angle modulation is considered to assess any potential benefits to performance and robustness. ${ }^{10,8}$ Angle of attack modulation provides increased responsiveness to high frequency density perturbations and may assist with uncertainties in trim angle of attack. Angle of attack control could be provided with movement of an internal ballast or possibly with an aerodynamic control surface. Fig. 14a, b and c show results from the same Monte Carlo, one case without angle of attack control, and one case with $\pm 5^{\circ}$ angle of attack modulation. As shown, alpha modulation results in a significant reduction in apoapsis dispersions, delta $\mathrm{V}$ and g's.

\section{K. Aeroheating Environments}

The aeroheating design trajectory utilized for TPS sizing was based on the highest heat load trajectory from an earlier

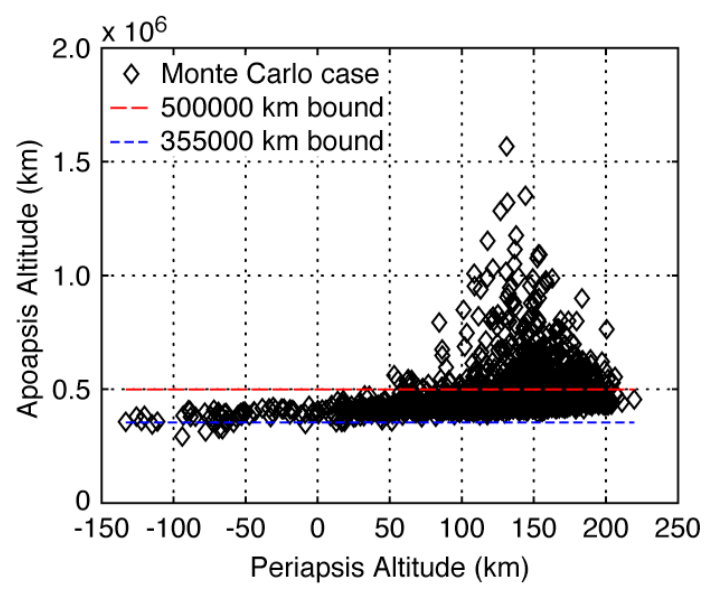

Figure 14a. Monte Carlo results without angle of attack modulation. ${ }^{8}$ 


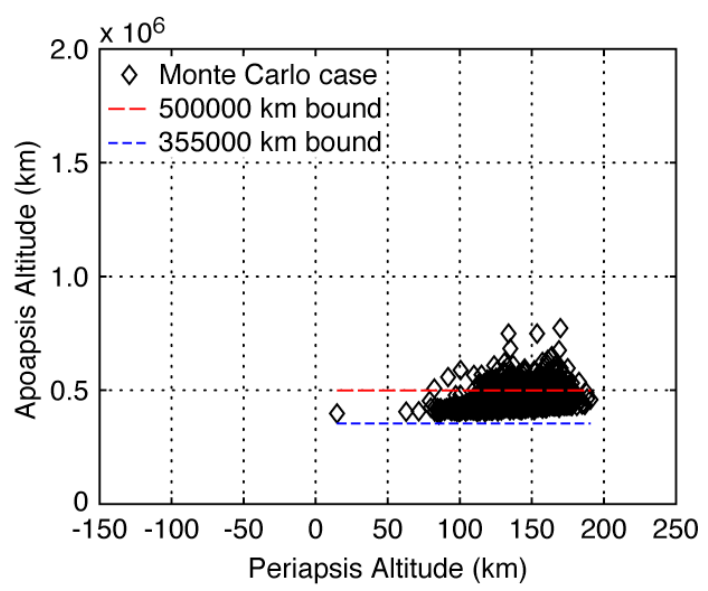

Figure 14b. Monte Carlo results with angle of attack modulation. ${ }^{8}$

version of the reference Monte Carlo and is based on navigated uncertainties of $\pm .51^{\circ} 3 \sigma$, the global range of Fminmax variability, rpscale $=1$, and the aerodynamic uncertainties described earlier. Fig. $15 \mathrm{a}$ illustrates the range of heat rate vs. heat load for the Monte Carlo compared to the lift up lift down range. The Monte Carlo heat rate range is 2050$3250 \mathrm{~W} / \mathrm{cm}^{2}$, and heat load range is $195-290 \mathrm{~kJ} / \mathrm{cm}^{2}$. The lift up, lift down peak heat range is $3155-1122$ $\mathrm{W} / \mathrm{cm}^{2}$, respectively. The lift up lift down heat load range is $185-442 \mathrm{~kJ} / \mathrm{cm}^{2}$, respectively. Typically the vehicle is designed to fly significantly closer to the center of the lift up lift down heat rate and load range than shown for these results. In this case, the guidance is designed to fly lift down early in the entry trajectory to allow successful targeting of the high-energy orbit apoapsis with the high ballistic coefficient vehicle. Fig. 15b illustrates the time variation of the stagnation point heating indicator for trajectory \#1647 compared to that for the minimum atmosphere lift up and maximum atmosphere lift down trajectories. This further illustrates that the design and corresponding Monte Carlo results are skewed toward the lift up high heat rate profiles.

Because of these results, the peak heat load trajectory from the Monte Carlo, \#1647, which also has $\sim 98$ percentile peak heat rate of 2001 trajectories, is selected as the reference trajectory for the TPS design, instead of the more traditional selection of the lift up trajectory for TPS selection, and lift down trajectory for TPS sizing.

Turbulent convective (LAURA and DPLR) and radiative (NEQAIR and RADEQUIL) computations are completed on the reference vehicle $\left(\mathrm{m} / \mathrm{C} \mathrm{dA}=895 \mathrm{~kg} / \mathrm{m}^{2} 2.88 \mathrm{~m}\right.$ flattened ellipsled) lift up and lift down trajectories and are utilized to estimate "low", "med", and "high" aeroheating environments along Monte Carlo trajectory \#1647. ${ }^{11}$

\begin{tabular}{|c|c|c|}
\hline & $\begin{array}{l}\text { Without } \alpha \\
\text { Modulation }\end{array}$ & $\begin{array}{c}\text { With } \alpha \\
\text { Modulation }\end{array}$ \\
\hline Apoapsis $-3 \sigma$ high, low & $\begin{array}{c}12.85 \mathrm{E} 5 \\
3.25 \mathrm{E} 5\end{array}$ & $\begin{array}{l}6.84 \mathrm{E} 5 \\
4.02 \mathrm{E} 5\end{array}$ \\
\hline Delta $V-3 \sigma$ high, low & $456 \mathrm{~m} / \mathrm{sec}$ & $288 \mathrm{~m} / \mathrm{sec}$ \\
\hline g's & 20 g's & 15 g’s \\
\hline Heat rate, load $-3 \sigma$ high & $\begin{array}{c}3130 \mathrm{~W} / \mathrm{cm}^{2} \text {, } \\
294 \mathrm{~kJ} / \mathrm{cm}^{2}\end{array}$ & $\begin{array}{c}2968 \mathrm{~W} / \mathrm{cm}^{2}, \\
277 \mathrm{~kJ} / \mathrm{cm}^{2}\end{array}$ \\
\hline
\end{tabular}

Figure 14c. Comparison of performance parameters with and without angle of attack modulation.

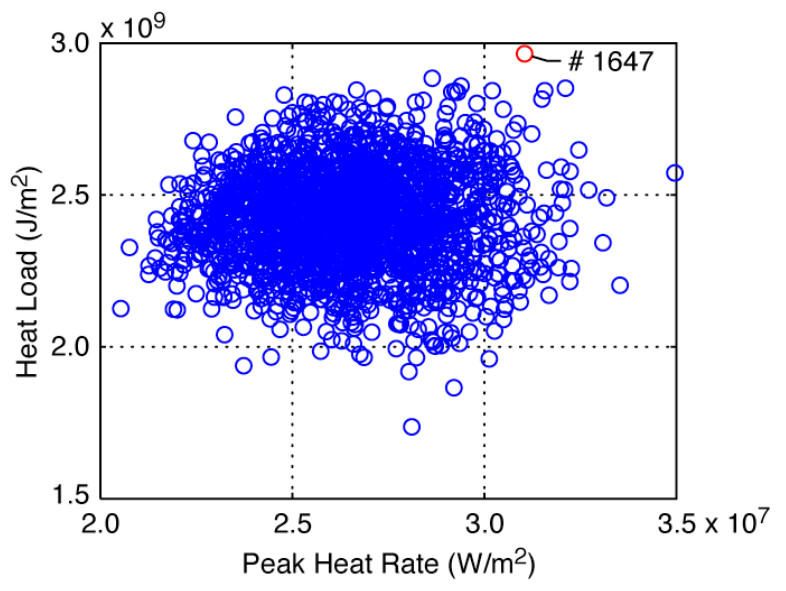

Figure 15a. Aeroheating design trajectory Monte Carlo results for convective stagnation point heat load vs. heat rate on a $1 \mathrm{~m}$ nose radius. Illustration of aeroheating design trajectory \#1647.

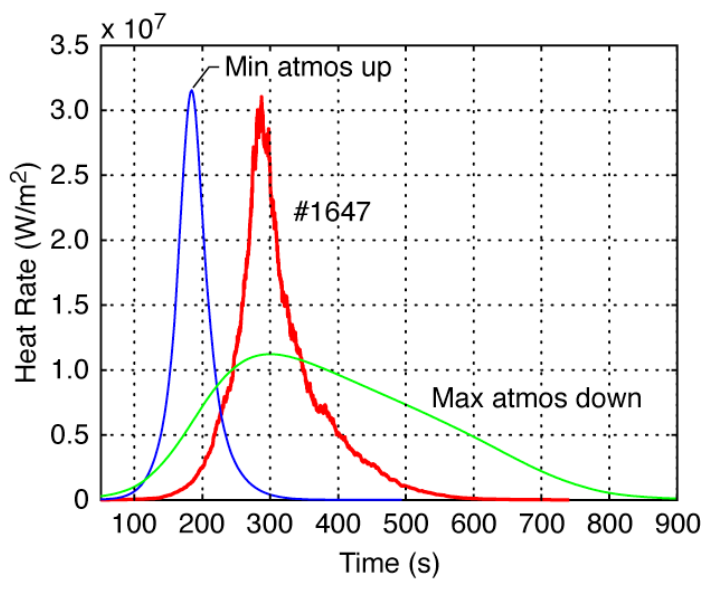

Figure 15b. Comparison of aeroheating profile for Monte Carlo trajectory \#1647 to lift upminimum atmosphere and lift down maximum atmosphere trajectories. 
Transition to turbulence prior to peak heating is expected due to significant ablation. Although only small differences, less than $10 \%$, result in comparisons of LAURA and DPLR laminar aeroheating rates, large differences occur in turbulent heating comparisons between LAURA and DPLR. The turbulence models used in the analyses included Cebeci-Smith algebraic or Wilcox k- $\Omega$ model with LAURA; Baldwin-Lomax algebraic turbulence with DPLR. None of the turbulence models were developed for, or validated in, high Mach H2-He flows.

Radiation is a significant contributor to the Neptune aeroheating environments. Both NEQAIR and RADEQUIL are utilized to estimate the radiative aeroheating environments. Significant differences between the two predictions result. To assist in understanding the aeroheating environmnents, analyses of Galileo are completed using NEQAIR and RADEQUIL for comparison with historical analysis and flight data, and for comparison to the Neptune Orbiter study vehicle. Current uncoupled analyses predict the same order of magnitude results, (between $45.4 \mathrm{~kW} / \mathrm{cm} 2$ and $78.5 \mathrm{~kW} / \mathrm{cm} 2$ for the total uncoupled convection and radiation aeroheating) as the historical uncoupled analysis $(63.3 \mathrm{~kW} / \mathrm{cm} 2$ shown in Table 2). Engineering approximations, Galileo analysis and flight data indicate that the effects of convection/radiation/ablation coupling must be considered. No tools exist for modeling convection/radiation/ablation for coupled 3-D flowfields. (Galileo was modeled with 1-D assumptions.) Higher fidelity coupled models are expected to reduce the environments compared to uncoupled results. Development and validation of methods for modeling coupled convection/radiation/ablation 3-D flowfields is one of the technologies identified as enabling as a result of this study.

Fig. 16 illustrates the division of the vehicle into zones, defined based on the vehicle structure, and to allow individual selection and sizing of TPS, based on

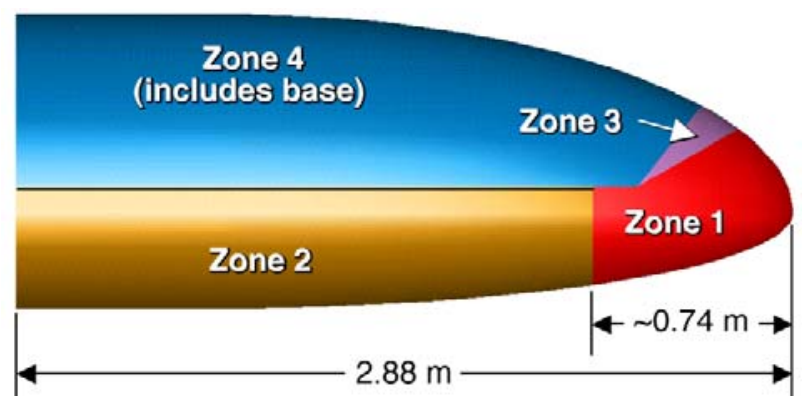

Figure 16. TPS zones. the point with the highest rates and loads in each zone, to reduce overall TPS mass. Zone 1 and 2 comprise the heatshield or forebody of the vehicle. Zones 3 and 4 including the base, comprise the backshell. The vehicle maximum diameter, also referred to as the waterline, occurs at the boundary of zone 2 and 4.

Table 2. Comparison of Neptune Orbiter reference concept to Galileo.

\begin{tabular}{lcc}
\hline \hline & Galileo (Jupiter Dec 1995) & Neptune Orbiter (study) \\
\hline Atmosphere composition & $86.2 \% \mathrm{H} 2,13.6 \% \mathrm{He}$ & $81 \% \mathrm{H} 2,19 \% \mathrm{He}$ \\
Inertial entry velocity $(\mathrm{km} / \mathrm{sec})$ & 60 & 29 \\
Atmos relative velocity $(\mathrm{km} / \mathrm{sec})$ & 48 & 31.4 \\
Inertial FPA $(\mathrm{deg})$ & -6.835 & -12.818 \\
Trajectory & Ballistic & Lifting, guided, controlled \\
Configuration & 44.25 deg sphere cone & Flattened ellipsled \\
Scale & $1.25 \mathrm{~m}$ diam $(.291 \mathrm{~m}$ nose rad) & $2.88 \mathrm{~m}$ length \\
M/CDA $\left(\mathrm{kg} / \mathrm{m}^{2}\right)$ & 224,229 & 895 \\
Heat pulse duration & $\sim 20 \mathrm{sec}$ & $\sim 200 \mathrm{sec}$ \\
Uncoupled stag pt peak heat rate & 63.3 & 16 \\
(convec + radiative) $\left(\mathrm{kW} / \mathrm{cm}^{2}\right)$ & 17.0 flight ${ }^{12}, 28.0$ analysis ${ }^{13}$ & $? ?$ \\
Coupled conv/rad/ablation $\left(\mathrm{kW} / \mathrm{cm}^{2}\right)$ & 14.6 & 12.9 \\
TPS stagnation point thickness $(\mathrm{cm})$ & 4.6 & 9.6 \\
TPS stagnation point recession $(\mathrm{cm})$ & Nose piece: fabricated from billet of & Nose: carbon phenolic (manufacturing \\
TPS material - heatshield & chopped molded carbon phenolic; & approach??); Wind: reduced density \\
& tape-wrapped carbon phenolic flank & carbon phenolic (dev/ testing?) \\
\hline \hline
\end{tabular}

Figures 17a and b show the range "low", "med", and "high" of peak heat rate and load estimated based on the CFD and radiative aeroheating analysis for the highest heat rate location on both the vehicle nose and the vehicle 


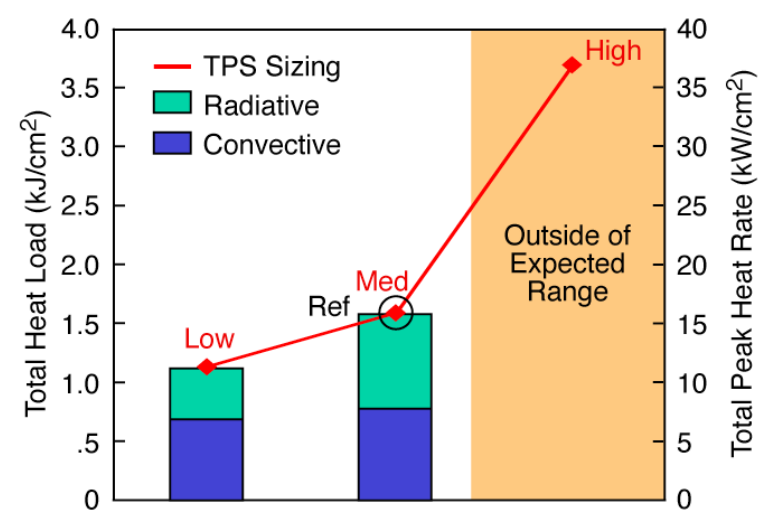

Figure 17a. Low, medium and high aeroheating results for zone 1 .

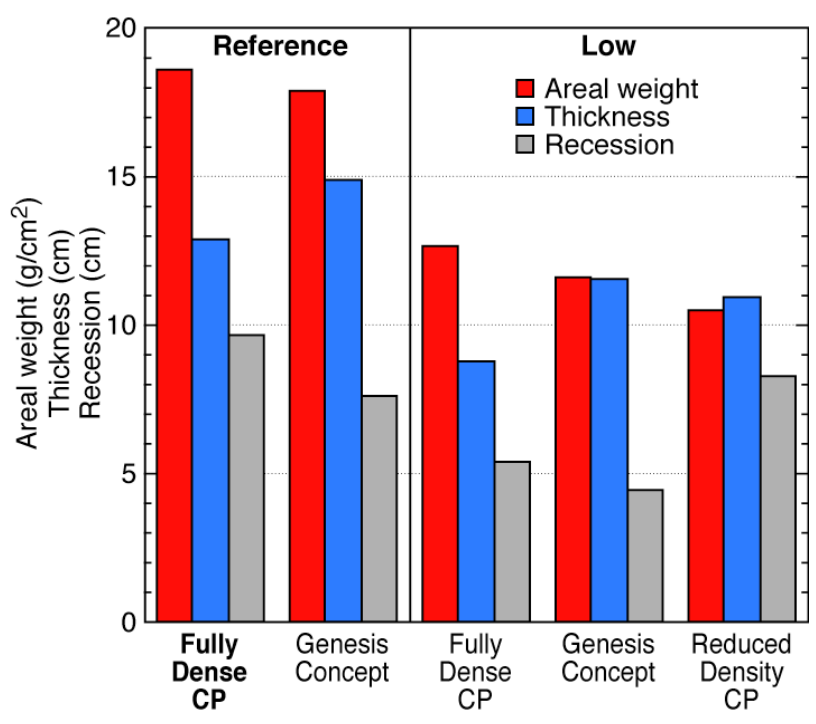

Figure 18a. TPS sizing results for zone $1 .{ }^{14}$

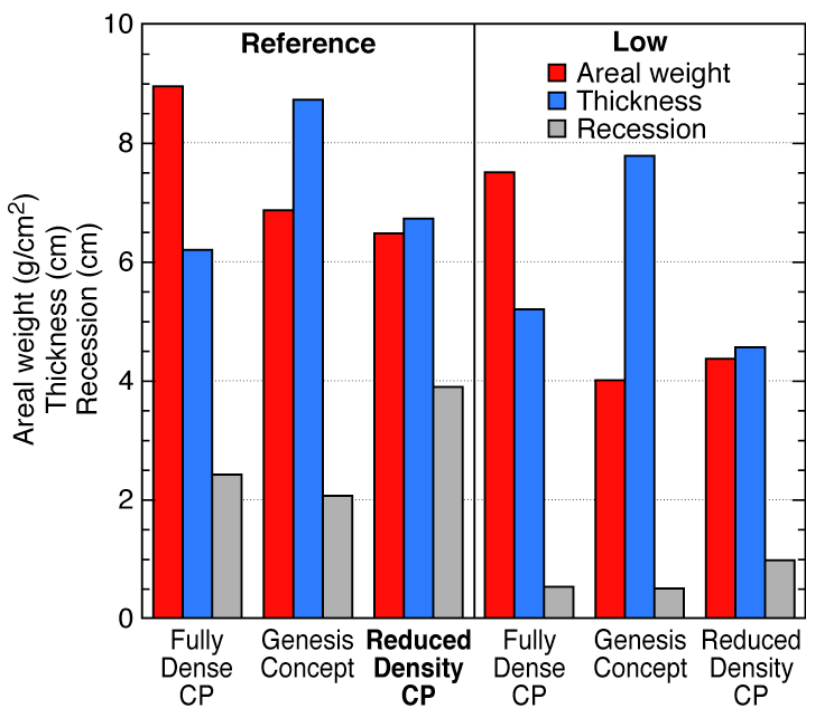

Figure 18b. TPS sizing results for zone $2{ }^{14}$

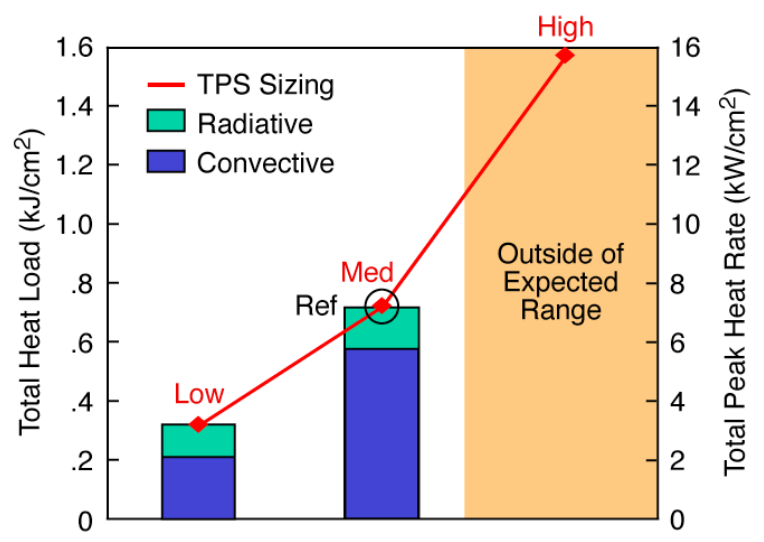

Figure 17b. Low, medium and high aeroheating results for zone 2.

wind side for trajectory \#1647. Note that after further analyses, including analysis of Galileo, the "high" estimate is well outside the expected range of aeroheating environments. These aeroheating environments are utilized to complete TPS selection and sizing.

TPS materials considered for the heatshield include carbon phenolic, reduced density carbon phenolic, and the Genesis carbon fiber form with carbon-carbon face sheet concept. Results of TPS sizing for the "Low" and "Medium" aeroheating are completed and shown in Fig. $18 \mathrm{a}$ and $\mathrm{b}$, for the nose and wind side, respectively. ${ }^{14}$ "Medium" levels are utilized for the Reference. The nose region is characterized by significant recession. Fabrication of the tape-wrapped carbon phenolic or Genesis concept may not be possible for these environments. As a result a fully dense carbon phenolic is selected for the nose region of the reference concept. However, TPS thickness in the nose region is beyond current TPS manufacturing experience for this shape and acreage. If the aeroheating rates and loads remain at the levels estimated, TPS manufacturing approaches will be enabling for the Neptune aerocapture mission. For the wind side, the reduced density carbon phenolic is selected, but additional work is needed to design and assess the ability of this type of concept to accommodate the heat rates estimated.

\begin{tabular}{lcc}
\hline \hline \multicolumn{1}{c}{ Zone } & Material & Mass (kg) \\
\hline Zone 1 (Nose) & Fully Dense CP & 204 \\
Zone 2 (Wind) & Reduced Density CP & 293 \\
Zone 3 (Lee, Nose) & PICA & 0.6 \\
Zone 4 (Lee, Nose) & SLA 561 & 58 \\
\hline \hline
\end{tabular}

Figure 18c. Reference concept TPS selected and corresponding CBE mass. ${ }^{14}$

\section{Aeroshell Structure}

Fig. 19a and $\mathrm{b}$ show the reference vehicle structural 


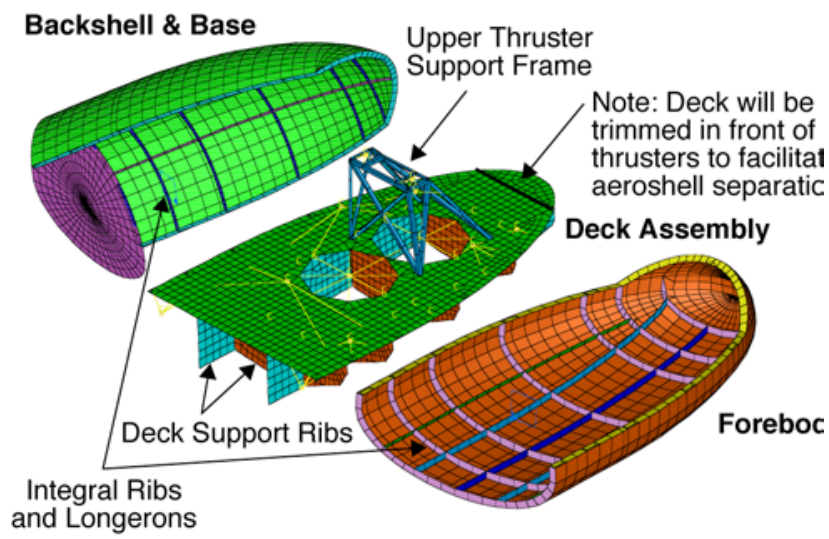

Figure 19a. Reference structural concept. ${ }^{15}$

\begin{tabular}{lc}
\hline \hline \multicolumn{1}{c}{ Component } & CBE Mass (kg) \\
\hline Aeroshell & \multicolumn{2}{c}{94.85} \\
$\quad$ Forebody & 44.9 \\
Backshell & 42.8 \\
Base & 7.15 \\
Deck & 21.6 \\
Deck Ribs & 17.9 \\
Tank Supt Rods & .42 \\
Thruster Supt Frame & 1.75 \\
Total Ellipsled Structure (CBE) & 136.5 \\
\hline \hline
\end{tabular}

Figure 19b. Reference concept CBE masses. ${ }^{15}$

concept and initial current best estimate of mass properties, respectively. ${ }^{15}$ Optimization of the structure after completion of the study indicates an opportunity to reduce the structural mass. ${ }^{15}$ Launch loads and stiffness requirements, and aerocapture entry loads are considered in the design and sizing of the structure. The load path for the orbiter on launch is from the cruise stage through the aeroshell to the deck. The TPS mass is considered to be a parasitic mass. The aeroshell forebody, backshell, base and deck are $2.54 \mathrm{~cm}$ thick sandwhich construction with $5052 \mathrm{Al}$ honecomb core and Graphite/Polymide face sheets. Integral monolithic blade stiffeners, longerons and ribs, are included for the forebody and backshell. The deck includes deck support ribs. 20 separation fittings attach the aeroshell forebody and backshell, and deck, which are used to separate the backshell and forebody from the deck after aerocapture.

\section{Mass Properties, Packaging}

Fig. 20a, b illustrate the packaging of the aerocapture orbiter, two probes and SEP propulsion module in the $5 \mathrm{~m}$ Delta IVH fairing ${ }^{3}$. Fig. 20c illustrates the packaging of the aerocapture orbiter. Table 3 includes the mass summary of the reference vehicle concept. The stack wet launch allocation is $5500 \mathrm{~kg}$. The aerocapture entry allocation is $2238 \mathrm{~kg}$ ( $\sim 2 \%$ greater than the allocation used in the performance analyses). 35\% margin (allocation $\mathrm{CBE}$ /allocation is included on dry mass, with $\sim 8 \%$ unallocated launch reserve. The aerocapture mass fraction is $59 \%$ of the orbiter dry mass based on growth masses ("MEV" in Table 3) with aerocapture propellant included (aeromaneuvering, periapsis raise and apoapsis correction); and 50\% without aerocapture propellant included.

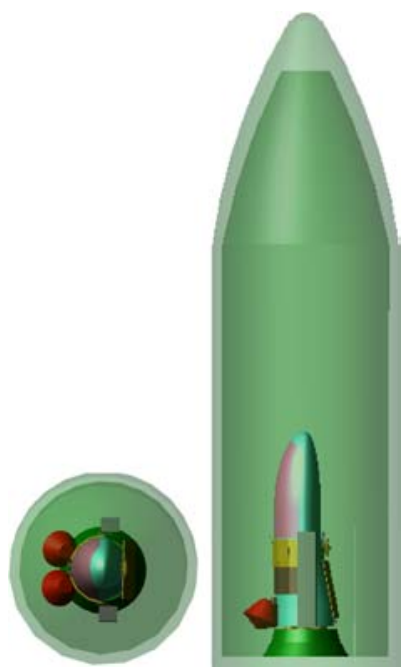

Figure 20a. Reference concept packaging in Delta IV, 5 m fairing. ${ }^{3}$

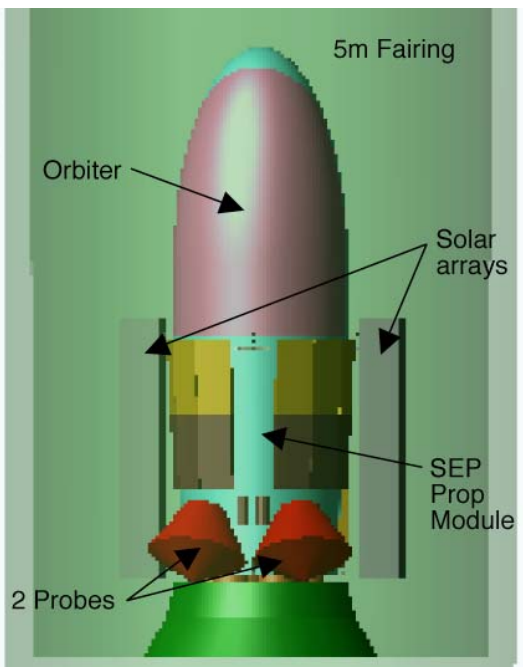

Figure 20b. Detail of reference concept packaging in Delta IV, 5 m fairing. ${ }^{3}$

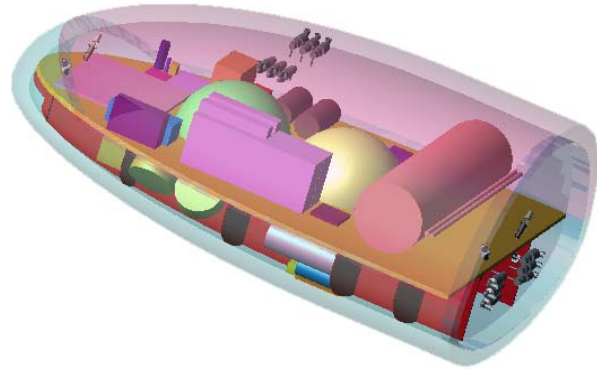

Figure 20c. Reference concept orbiter packaging. ${ }^{3}$ 
Table 3. Reference concept mass property summary. ${ }^{3}$

\begin{tabular}{|c|c|c|c|c|c|}
\hline Mass in $\mathrm{kg}$ & CBE & Cont & TVEV & TVarg & AIIOC \\
\hline Launch Capability & & & & & 5964 \\
\hline Launch Reserve & & & & $8.4 \%$ & 463 \\
\hline Launch Wet Alloc & & & & & 5500 \\
\hline SEPLVAdapter & 48 & $30.0 \%$ & 62 & $12.2 \%$ & 10 \\
\hline Xenon & $9 / 3$ & $10.0 \%$ & 1070 & $0.0 \%$ & 1070 \\
\hline SEP Dry Mass & 1134 & $29.5 \%$ & 1468 & $20.0 \%$ & 1762 \\
\hline Cruise Hydrazine & & & 111 & & 111 \\
\hline Cruise Probes & 159 & $30.0 \%$ & 207 & $20.0 \%$ & 249 \\
\hline A/C Entry Alloc & & & & & 2238 \\
\hline A/C Aeroshell/IPS & 736 & $30.0 \%$ & 957 & $20.0 \%$ & 1149 \\
\hline ACC ACS Prop & & & 22 & & 22 \\
\hline A/C Peri Raise Prop & & & 139 & & 139 \\
\hline Orbit Wet Alloc & & & & & 928 \\
\hline Orbit Prop & & & 124 & & 124 \\
\hline Orbit Dry Mass & 524 & $27.3 \%$ & 667 & $20.4 \%$ & 804 \\
\hline \multicolumn{6}{|c|}{$\begin{array}{l}\text { CBE }=\text { Current Best Estimate } \\
\text { Cont }=\text { Contingency }=(\text { MEV-CBE }) / \mathrm{CBE} \\
\mathrm{MEV}=\text { Maximum } \text { Expected Value } \\
\text { Marg }=\text { Margin }=(\text { Alloc-MEV }) / \mathrm{MLV} \\
\text { Alloc = Allocation }\end{array}$} \\
\hline
\end{tabular}

\section{N. Comparison to All-Propulsive Mission}

Several alternate mission concepts are shown in Table $4^{4}$ for comparison to the reference concept labeled "Option B2". Each option shows the mass that can be delivered to Neptune prior to insertion, labeled "Pre-NOI Net Delivered Mass.," and the mass required to capture into Neptune orbit. For the chemical insertion the chemical propellant and chemical dry mass are calculated based on the "Pre-NOI Net Delivered Mass". For the aerocapture system, the "Aerocapture System" mass is based on the reference concept and is fixed at $1119 \mathrm{~kg}$. The "Payload in Neptune Orbit" is defined based on the reference concept and is $792 \mathrm{~kg}$. "System Margin" represents either a surplus or deficit in the capability of the system to deliver the $792 \mathrm{~kg}$ into orbit. The System Margin should be between $15-20 \%$ for adequate margin.

To determine the benefit of aerocapture compared to an all-propulsive system, the aerocapture system that delivers the maximum mass to Neptune orbit (Delta IVH, EJGA, SEP, Aero) can be compared to the all-propulsive system that delivers the maximum mass to Neptune orbit (Delta IVH, EJGA, SEP, Chem), each for the same launch vehicle. For the all-propulsive option, a maximum of $1167 \mathrm{~kg}$ can be delivered into Neptune orbit (zero margin). For the aerocapture option, assuming a fixed aerocapture mass fraction of 59\% (includes aerocapture deltaV), 1614 $\mathrm{kg}$ can be delivered into Neptune orbit (zero margin). Therefore aerocapture results in approximately 1.4 times more mass in Neptune orbit as compared to an all-propulsive system.

In addition, Table 4 shows significant trip time savings for the aerocapture systems as compared to the allpropulsive systems. 
Table 4. Comparison to alternate mission concepts. ${ }^{4}$

\begin{tabular}{|c|c|c|c|c|c|c|c|c|c|}
\hline \multirow{4}{*}{$\begin{array}{l}\text { Launch Vehicle } \\
\text { Gravity Assist } \\
\text { Earth to Neptune Prop System } \\
\text { NOI Prop System }\end{array}$} & \multicolumn{7}{|c|}{ Delta IV H } & \multirow{2}{*}{\multicolumn{2}{|c|}{$\begin{array}{c}\text { Atlas 551 } \\
\text { EJGA }\end{array}$}} \\
\hline & \multirow{3}{*}{\begin{tabular}{|c|} 
VEJGA \\
Chem \\
Chem
\end{tabular}} & \multicolumn{4}{|c|}{ EJGA } & \multirow{2}{*}{\multicolumn{2}{|c|}{$\begin{array}{l}\text { VJGA } \\
\text { SEP }\end{array}$}} & & \\
\hline & & \multicolumn{2}{|c|}{ Chem } & \multicolumn{2}{|c|}{ SEP } & & & \multirow{2}{*}{\begin{tabular}{c|} 
Chem \\
Aero
\end{tabular}} & \multirow{2}{*}{$\begin{array}{c}\text { SEP } \\
\text { Aero }\end{array}$} \\
\hline & & Aero & Aero & Chem & Aero & Chem & Aero & & \\
\hline Option & A1 & $A 2$ & $A 2$ & B1 & B2 & B1 & B2 & $A 2$ & B2 \\
\hline Cruise Time to Neptune (yrs) & 15.0 & 10.8 & 11.8 & 15.0 & 10.5 & 15.0 & 10.3 & 11.8 & 10.5 \\
\hline Launch Year & 2014 & 2016 & 2014 & 2016 & 2016 & 2017 & 2017 & 2014 & 2016 \\
\hline Launch C3 (km2/sec2) & 15.6 & 26.0 & 47.3 & 13.5 & 13.6 & 17.0 & 18.4 & 47.3 & 9.1 \\
\hline SEP Power (kW, EOL) & & & & 30 & 30 & 30 & 30 & & 30 \\
\hline Inertial Entry Velocity (km/s) & & 29 & 29 & & 29 & & 29 & 29 & 29 \\
\hline Neptune Cruise Chem DV $(\mathrm{m} / \mathrm{s})^{1}$ & 3429 & 1413 & 357 & & & & & 357 & \\
\hline NoI Chem DV $(\mathrm{m} / \mathrm{s})^{1}$ & 2300 & & & 2871 & & 2781 & & & \\
\hline & 9 & & & 6 & & 6 & & 6 & \\
\hline Launch Capability & 7012 & 5695 & 3550 & 6543 & 6532 & 6130 & 5964 & 2630 & 4850 \\
\hline Propellant Mass ${ }^{2,3}$ & 4158 & 2040 & 376 & 655 & 809 & 1025 & 1070 & 279 & 713 \\
\hline LV to Prop Module Adapter & 62 & 62 & 62 & 62 & 62 & 62 & 62 & 62 & 62 \\
\hline Prop Module Dry Mass & 806 & 542 & 289 & 1437 & 1449 & 1465 & 1468 & 243 & 1441 \\
\hline Chem Prop Mod to Payload Adapter & 40 & 40 & 40 & & & & & 40 & \\
\hline Pre-NOI Separated Mass ${ }^{10}$ & 318 & 318 & 318 & 318 & 318 & 318 & 318 & 318 & 318 \\
\hline $\begin{array}{c}\text { Pre-NOI Net Delivered Mass } \\
\end{array}$ & 1628 & 2694 & 2464 & 4071 & 3895 & 3260 & 3046 & 1688 & 2315 \\
\hline Aerocapture System ${ }^{4}$ & & 1119 & 1119 & & 1119 & & 1119 & 1119 & 1119 \\
\hline NOI Chem Propellant Mass ${ }^{8}$ & 966 & & & 2417 & & 1898 & & & \\
\hline NOI Chem Dry Mass & 280 & & & 487 & & 413 & & & \\
\hline Payload in Neptune Orbit & 792 & 792 & 792 & 792 & 792 & 792 & 792 & 792 & 792 \\
\hline System Margin = LV-MEV & (409) & 783 & 553 & 375 & 1984 & 157 & 1135 & (223) & 404 \\
\hline System Margin \% $\%$ (LV-MEV)/MEV & $-5.5 \%$ & $15.9 \%$ & $18.5 \%$ & $6.1 \%$ & $43.6 \%$ & $2.6 \%$ & $23.5 \%$ & $-7.8 \%$ & $9.1 \%$ \\
\hline $\begin{array}{l}\text { MEV: Maximum Expected Value = best estimat } \\
\text { Assumptions and Notes: }\end{array}$ & $\mathrm{e}+30 \% \mathrm{cc}$ & intingenc & & & & & & & \\
\hline All masses are MEV mass listed in $\mathrm{kg}$ & & & & & & & & & \\
\hline${ }^{1}$ Includes 5\% DV contingency & & & & & & & & & \\
\hline${ }^{2}$ Chem Propellant mass calculated using "Launch & Capability" & as syster & total mas & s; Chem Is & $=325 \mathrm{se}$ & & & & \\
\hline${ }^{3}$ SEP Propellant mass calculated using "Launch C & apability" a & s system & total mass & includes & $0 \%$ prop $n$ & nass cont & ngency & & \\
\hline${ }^{4}$ Aerocapture System Mass: aeroshell structure, T & $\mathrm{PS}$, and $\mathrm{D}$ & to achie & $28766 \times 4$ & $88,000 \mathrm{~km}$ & & & & & \\
\hline${ }^{6}$ Propellant mass and Prop Module Dry Mass for $\mathrm{S}$ & EP / Chem & options i & cludes pro & pellant and & dry mass & & & & \\
\hline $\begin{array}{l}\text { both SEP and chemical stages } \\
{ }^{7} \text { Neptune Aerocapture Study Reference Mission }\end{array}$ & & & & & & & & & \\
\hline${ }^{8}$ Chem Propellant mass calculated using "Pre-NOI & Net Delive & ed Mass & as Initial $m$ & nass; Cher & $I s p=325$ & & & & \\
\hline${ }^{9}$ Total Cruise+NOI DV split equally between two st & ages; l.e. & ruise de & $-V$ is st & & & & & & \\
\hline${ }^{10}$ Includes Probes and $\sim 100 \mathrm{~kg}$ of cruise hydrazine & & & & & & & & & \\
\hline
\end{tabular}

\section{O. Summary and Technology}

Aerocapture can deliver 1.4 times more mass to Neptune than an all-propulsive system for the same launch vehicle. Aerocapture is feasible and performance is adequate for the Neptune aerocapture mission. Monte Carlo simulation results show $100 \%$ success for all cases including conservative assumptions on atmosphere and navigation. Additional analyses are required to assess the amount of surface recession from coupled 3-D convective/radiative/ablation analyses, determine the aerodynamics and uncertainties resulting from time and path dependent shape change, and evaluate the effect on guidance and control algorithm design, and performance. The Neptune spacecraft can be successfully packaged in an aeroshell and result in $\sim 8 \%$ unallocated mass while meeting the required mass margins.

Technologies identified in the study as requiring development are grouped into three categories; enabling technologies, strongly enhancing technologies and enhancing technologies. Technologies annotated with an asterisk are categorized based on current understanding. Additional assessment could change the categories.

The enabling technologies identified include

- TPS Manufacturing. TPS thicknesses are beyond current manufacturing experience for carbon phenolic for this shape and acreage.

- Aerothermodynamic methods and validation 
- Aerothermodynamics are characterized by high radiative and convective aeroheating, coupled convection/radiation/ablation, and significant surface recession with effects on vehicle aerodynamics on a more complex shape.

- Coupled convection/radiation/ablation capability for three-dimensional flowfields is needed for definition of aeroheating environments, TPS requirements, and vehicle shape change.

- An approach is needed to determine and represent the aerodynamics/uncertainties on the time varying path dependent shapes and corresponding masses in an aerodatabase and simulation.

The strongly enhancing technologies identified include

- Guidance Algorithm* - Existing guidance algorithms have been demonstrated to provide adequate performance. However, improvements are possible to improve performance, to determine the ability to reduce heat loads and to accommodate time varying, path dependent shape and ballistic coefficient change

- Flight Control Algorithm* - Algorithms must be able to accommodate shape change uncertainties

- Atmosphere Modeling - Neptune General Circulation Model output is needed to represent the dynamic variability of the atmosphere.

- Reduced Mass TPS concepts, ex., reduced density carbon phenolic, could be utilized to decrease aeroshell mass.

- Utilizing the TPS as a structural element may reduce the combined structure plus TPS mass.

- Alpha Modulation* reduces the dispersions in apoapsis, provides additional and more rapid response to density perturbations, and provides additional margin for trim angle of attack uncertainties.

- Dual Stage MMRTGs

- Deployable Ka-Band HGA

The enhancing technologies identified include

- Automated navigation, improved optical navigation camera.

- Miniaturized ACS components.

- Lower Mass, Power Science Instruments

\section{Future Work}

Several areas are recommended for future systems analysis in addition to the specific technology items listed above. Recommendations are as follows.

Complete partial design cycles for one or more intermediate (between $2.88 \mathrm{~m}-5.5 \mathrm{~m}$ length scale) vehicle sizes. There may be a minimum mass vehicle between the $2.88 \mathrm{~m}$ and $5.5 \mathrm{~m}$ length vehicle. The trade is surface area vs. areal density of the combined TPS and structure.

The current design has $460 \mathrm{~kg}$ unallocated mass. In addition, interplanetary trajectory designs have resulted in increased delivered mass capability. Several design changes can be considered within the increased mass capability. For example, an increased vehicle scale may reduce aeroheating rates and loads and the corresponding surface recession and TPS thickness required.

Additional trades that can be completed include a further assessment of chemical vs. SEP cruise; additional systems analysis considering angle of attack modulation; revisiting the $\mathrm{L} / \mathrm{D}=.6$ vehicle; consideration of a symmetric version of the flattened ellipsled i.e. an elliptic upper section, in addition to elliptic lower and section; utilization of the TPS as a structural element; and consideration of variable thickness TPS for TPS mass reduction.

\section{Acknowledgments}

The author would like to acknowledge and thank the team members of the NASA Aerocapture Systems Analysis Team at ARC, JPL, JSC, LaRC and MSFC for their work and contributions to the Neptune Aerocapture Systems Analysis Study and to this paper. Thank you to Paul Wercinski, Aerocapture Systems Analysis Study Peer Review Chair, and the peer review panel members for review of this work and helpful comments and recommendations. Thank you to Code S In Space for sponsoring this work. Thank you to Anne Costa for preparing this paper for publication. 


\section{References}

${ }^{1}$ Lockwood, M.K., “Titan Aerocapture Systems Analysis,” AIAA-2003-4799, July, 2003.

2"Neptune Orbiter/Probes 2001-12" TeamX 6,7,14 December 2001.

${ }^{3}$ Bailey, R.W., Hall, J.L., Spilker, T.R., O’Kongo, N., "Neptune Aerocapture Mission and Spacecraft Design Overview," AIAA-2004-3842, July 11-14, 2004.

${ }^{4}$ Noca, M., Bailey, R.W., "Mission Trads for Aerocapture at Neptune,” AIAA-2004-3843, July 11-14, 2004.

${ }^{5}$ Edquist, K.T., Prabhu, R.K., Hoffman, D.A., and Rea, J.R., "Configuration, Aerodynamics and Stability Analysis for a Neptune Aerocapture Orbiter," AIAA-2004-4953, August 16-19, 2004.

${ }^{6}$ Haw, R. “Aerocapture Navigation at Neptune," AAS-03-643, August 3-7, 2003.

${ }^{7}$ Justus, C.G., Duvall, A., Keller, V.W. "Atmospheric Models for Aerocapture Systems Studies,” AIAA-2004-4952, August 16-19, 2004.

${ }^{8}$ Starr, B.R., Powell, R.W., "Aerocapture Performance Analysis for a Neptune- Triton Exploration Mission," AIAA-20044955, August 16-19, 2004.

${ }^{9}$ Cobleigh, B.R., "Development of the X-33 Aerodynamic Uncertainty Model," NASA TP-1998-206544, April 1998.

${ }^{10}$ Masciarelli, J., Westhelle, C.H., Graves, C.A., "Aerocapture Guidance Performance for the Neptune Orbiter," AIAA-20044954, August 16-19, 2004.

${ }^{11}$ Hollis, B., Takashima, N., Sutton, K., Wright, M., Olejniczak, J., Prabhu, D., "Preliminary Convective-Radiative Heating Environments for a Neptune Aerocapture Mission," AIAA- 2004-5177, August 16-19, 2004.

${ }^{12}$ Tauber, M.E., NASA TM-1999-208796, Sep. 1999

${ }^{13}$ Moss, J.N., Dimmonds, A.L., AIAA 82-0874

${ }^{14}$ Laub, B., Chen, Y.-K., "TPS Challenges for Neptune Aerocapture," AIAA-2004-5178, August 16-19, 2004.

${ }^{15}$ Dyke, R.E., Hrinda, G., "Structural Design for a Neptune Aerocapture Mission,” AIAA-2004-5179, August 16-19, 2004. 